\title{
Indoor wood-decay basidiomycetes: damage, causal fungi, physiology, identification and characterization, prevention and control
}

Olaf Schmidt

Published online: 7 September 2007

(C) German Mycological Society and Springer-Verlag 2007

Erratum to: Mycol Progress

DOI 10.1007/s11557-007-0534-0

Due to an unfortunate error the category of the article was incorrect.

The correct category is Review Article.

The online version of the original article can be found at http://dx.doi. org/10.1007/s11557-007-0534-0.

O. Schmidt $(\bowtie)$

Department of Wood Biology, University of Hamburg,

Leuschnerstr. 91,

21031 Hamburg, Germany

e-mail: o.schmidt@holz.uni-hamburg.de 